Rev. Latinoam. Psicopat. Fund., São Paulo, 18(2), 383-393, jun. 2015

http://dx.doi.org/10.1590/1415-4714.2015v18n2p383.14

\title{
Um Hospital Geral e suas concepções da loucura*1
}

\author{
Jhéssyca Dias de Carvalho*2 \\ Cristina Bastos Alves Lins*3
}

\begin{abstract}
Objetivo: Conhecer as concepções acerca da loucura produzidas por profissionais que trabalham em um Hospital Geral. Procedimentos: foram realizados grupos de conversação, e seus resultados estudados a partir da Análise do Discurso e História da Loucura de Michel Foucault. Conclusões: as estruturas dos manicômios permanecem instaladas em sua concretude e na mentalidade das pessoas, que continuam a acreditar que o louco precisa ser controlado para atender as demandas sociais.
\end{abstract}

Palavras-chave: Saúde mental, análise do discurso, concepções da loucura, Hospital Geral e loucura

${ }^{* 1}$ O trabalho foi realizado na Fundação Hospital de Clínicas Gaspar Vianna - FHCGV (Belém, PA, Br), no ano de 2014, para obtenção de título de especialista em Atenção à Saúde Mental no ano de 2015 e apresentado no auditório da mesma instituição, também no ano de 2015.

*2,3 Universidade do Estado do Pará - UEPA e Fundação Hospital de Clínicas Gaspar Vianna - FHCGV (Belém, PA, Br). 


\section{Apresentação}

O presente artigo surgiu a partir da pesquisa realizada para a obtenção do título de especialista em Saúde Mental do Programa de Residência Multiprofissional em Atenção à Saúde Mental realizada pela Universidade Estadual do Pará - UEPA e Fundação Hospital de Clínicas Gaspar Vianna - FHCGV. Foi construído com os resultados obtidos em uma pesquisa de caráter qualitativo e descritivo, considerando, principalmente, a Análise do Discurso proposta por Michel Foucault e seus estudos acerca da História da Loucura que teve como objetivo conhecer as concepções acerca da loucura produzidas por diferentes profissionais de saúde que compõem as equipes de trabalho da Fundação Hospital de Clínicas Gaspar Vianna. A coleta de dados se deu em três encontros denominados de grupos de conversação, com duração de noventa minutos cada um. A facilitadora dos grupos se utilizou de algumas perguntas norteadoras para provocar a conversação, que tinha como tema central a loucura. A partir da conversação, aconteceu a contação de histórias (Mcnamee \& Gergen, 1998) e, consequentemente, saberes foram construídos possibilitando conhecer as concepções da loucura e do louco, a partir das histórias que contaram os três grupos de conversação. $\mathrm{Na}$ análise, foi possível identificar os discursos relacionados às seguintes temáticas: a) a loucura como distúrbio, transtorno e descontrole; b) o louco como alguém que gera medo e insegurança; c) o tratamento; e d) a Reforma Psiquiátrica. Foi possível identificar que apesar das conquistas alcançadas pela Reforma Psiquiátrica, muitos dos modelos vigentes em séculos passados perduram nas concepções da loucura que os profissionais apresentam ainda hoje. Com isso, nota-se que as estruturas dos manicômios permanecem instaladas, seja em sua concretude, seja na mentalidade das pessoas, as quais continuam a acreditar que o louco precisa ser controlado, normalizado, equilibrado, para atender as demandas sociais. 


\section{PRIMEIROS PASSOS}

\section{Percurso metodológico}

Para que se pudesse conhecer as concepções acerca da loucura produzidas pelos diferentes profissionais que compõem a FHCGV, a pesquisa foi realizada com a participação de trabalhadores de saúde que compõem o quadro funcional dos seguintes setores do hospital: Clínica Médica, Clínica Cirúrgica e Serviço de Apoio Diagnóstico. Foram participantes da pesquisa homens e mulheres, com nível de escolaridade variando entre Ensino Médio e Superior, que, após conhecerem os objetivos e método do processo, aceitaram assinar o Termo de Consentimento Livre e Esclarecido (TCLE). Não puderam participar da pesquisa profissionais psis (psiquiatras e psicólogos); profissionais que já haviam trabalhado nas áreas da Psiquiatria e/ou Saúde mental; e, profissionais de empresas terceirizadas à FHCGV.

$\mathrm{Na}$ primeira etapa da coleta de dados, os profissionais foram convidados a participar da pesquisa mediante contato direto e presencial. Após o aceite, foi esclarecido aos mesmos que a coleta de dados seria realizada por meio de grupos de conversação, cujo tema seria a loucura.

Foram realizados três grupos de conversação, com duração de noventa minutos cada um. Estes grupos aconteceram dentro da instituição hospitalar. Um encontro grupal foi realizado com a equipe da Clínica Médica, outro com a equipe da Clínica Cirúrgica e o terceiro foi com a equipe do Apoio Diagnóstico. Tais encontros foram realizados em dia, hora e locais previamente combinados.

Os profissionais que se dispuseram a participar da pesquisa foram convidados a conversar sobre determinadas questões relativas à loucura, tais como: o que eles entendiam por loucura; quem é o louco; se conhecem ou convivem com alguém considerado louco; se conhecem o tratamento atual dispensado ao louco; se já ouviram falar da Reforma Psiquiátrica e o que pensam a respeito dela.

Os grupos de conversação foram escolhidos para nortear esta pesquisa tendo como embasamento teórico a forma de pesquisa proposta por Spink (2008), a qual reposiciona o pesquisador no espaço que ele ocupa, colocando-o como um indivíduo que irá conversar com os demais sobre determinado tema no cotidiano, e que, portanto, nos grupos, ocupa a função de facilitador.

$\mathrm{Na}$ segunda etapa, o material resultante dos grupos de conversação foi estudado por meio da análise do discurso, a qual, segundo Foucault (2008), se desenvolve a partir da afirmativa de que o discurso é prática, e que não se deve interpretar o que há por trás daquilo que é dito, pois este não se esgota em uma mera explicação do que estaria sendo exposto através da linguagem.

Os benefícios deste estudo serão os conhecimentos produzidos a partir da análise dos resultados, os quais podem servir de parâmetros de avaliação sobre o que mudou ou o que ainda precisa ser mudado acerca da concepção da loucura em 
nossa cultura, fato importante para conseguirmos alcançar a proposta de inclusão social do louco.

\section{Resultados e discussão}

A partir das conversações entre os profissionais, nos grupos, aconteceram as contações de histórias (Mcnamee \& Gergen, 1998) e, consequentemente, saberes foram construídos e as concepções de loucura foram sendo desvendadas.

Da análise dos relatos construídos nos grupos de conversação, foi possível identificar os discursos, relacionados às seguintes temáticas: a) a loucura como distúrbio, transtorno e descontrole; b) o louco como alguém que gera medo e insegurança; c) o tratamento; e d) a Reforma Psiquiátrica.

As conversações evidenciaram diferentes concepções acerca da loucura, concepções que não podem ser consideradas nem certas nem erradas, mas apenas concepções diferenciadas entre si e que remontam desde o período da Antiguidade até a Modernidade.

\section{a) A loucura como distúrbio, transtorno e descontrole}

Os grupos relacionaram a loucura a um distúrbio que talvez esteja relacionado a um fator hereditário, questões familiares, ambientais e outras situações que podem de alguma forma desencadeá-la, deixando a pessoa transtornada, fora de si, fazendo coisas que não deveria, como se estivesse em outro mundo, o que lembra os estudos de Foucault (1972) em que afirmou que foi a partir da Modernidade que a loucura passou a ser relacionada a um indivíduo que está em um estado de alienação de si mesmo e do mundo que o rodeia. Dessa forma, ele estaria alheio a qualquer noção do que seria certo ou errado, e, portanto, seria isento de qualquer ato que pudesse praticar.

Para estes profissionais de saúde, a loucura também é compreendida como um erro, como algo desviante da norma estabelecida, bem como apontou Foucault (1972) em seus estudos sobre a loucura, onde afirmou que na Era Clássica a loucura desemboca em um território inteiramente moral, em que o Mal passa a não ser mais o castigo ou o fim dos tempos, mas apenas erro e defeito. Muitos dos cantos das poesias de Brant, que retratavam a Nau dos loucos, deixavam claras as características dos passageiros que a ocupavam: eram os avaros, os delatores, os bêbados, aqueles que se entregam à desordem e devassidão.

De uma forma geral, tudo aquilo que o homem concebia como irregularidades de conduta era considerado loucura, o que justificava o internamento dos loucos, pois era necessário manter a ordem na sociedade da época. Então, pode-se inferir que a loucura ainda hoje está relacionada a questões éticas e morais, pois 


\section{PRIMEIROS PASSOS}

na impossibilidade de corresponder às normativas impostas pela sociedade, o louco acaba sendo considerado um ser diferente dos demais, que deve ser tratado com vistas a sua normalização. E se, na Era Clássica, os internamentos funcionavam como espaços de segregação deste louco a fim de manter a ordem social, hoje em dia é por meio das contenções que se tenta normalizá-lo.

Nas conversações foi compartilhado que o louco é alguém que necessita de contenção para que possa ser controlado, já que não se pode prever o momento em que ele poderá ficar agressivo e/ou agitado. Tal agressividade e agitação do louco foram relacionadas pelos grupos como comportamentos desviantes que, na ausência de tratamento adequado, transformou-se em loucura. Com estes resultados, é possível identificar que cada cultura dita modelos de conduta a seus membros e os que desviam tais modelos e se comportam de forma amoral sem respeitar os padrões sociais seriam os loucos e a loucura seria uma falha do grupo social (Foucault, 1972).

Os conversadores também relacionaram a loucura a questões espirituais, sendo que ela iniciaria a partir de algum conflito espiritual que na ausência de tratamento adequado tornar-se-ia loucura e que, a partir deste momento, já precisaria de medicamentos. Tais pensamentos nos reportam à Idade Média quando as concepções que se tinha da loucura eram permeadas de ideias demonistas de que os loucos eram possuídos por espíritos malignos, e que, portanto, estariam sujeitos aos desígnios de Deus. Era como se o mundo necessitasse de outro personagem para excluir e na gradativa extinção dos leprosos, foram tomando seu lugar os loucos, que necessitavam de salvação espiritual e ao mesmo tempo proporcionavam a salvação daqueles que os excluíam (Foucault, 1972).

Para os participantes, a loucura como doença, distúrbio, transtorno, descontrole, desvio de conduta, deve ser controlada para que o louco não ofereça riscos à sociedade nem cause nenhum incômodo ou estranhamento.

\section{b) O louco como alguém que gera medo e insegurança}

Para os profissionais deste Hospital Geral, o louco é alguém que gera medo e insegurança, já que ele é um inconsequente, não tem controle sob seus atos, podendo ser violento verbal e/ou fisicamente para com terceiros. A periculosidade do louco remonta da Idade Clássica, período em que os loucos eram privados de sua liberdade nos internamentos junto àqueles que perturbavam a ordem social (Foucault, 1972).

Atualmente o aparelho controlador do louco seria o saber médico e as contenções, pois ele até pode voltar ao convívio de sua família e ser reinserido na sociedade, desde que não apresente mais os comportamentos que apresenta em seus momentos de surto. Estes causam estranhamento, medo e insegurança aos que supostamente ocupam e se mantém de alguma forma ao lado da normalidade.

Ainda que os grupos façam a distinção entre os loucos em surto e aqueles que já estariam controlados pelas contenções, prevalece ainda o medo em relação a ambos. 
Então, é possível constatar que ainda hoje é preciso lidar com o louco de forma a controlá-lo de alguma maneira, se no Classicismo haviam os internamentos para realizar este controle, hoje o que há são as contenções, tanto químicas quanto mecânicas, as clínicas das instituições hospitalares e os novos serviços como os CAPS (Centro de Atenção Psicossocial). Muitas vezes tais formas são compreendidos apenas tendo este caráter de controlar os loucos para que não incomodem e nem sejam agressivos com os demais, o que demonstra íntima relação com os estudos de Foucault (1972) sobre o nascimento do hospital. Este autor explicou que quando o hospital surgiu, ele não tinha função curativa, mas apenas de segregar e oferecer alguma assistência aos indesejados pela sociedade da época, porém, a partir do século XVIII, tem-se a disciplina sendo expandida a vários setores da sociedade para manter a ordem e com o surgimento do interesse da classe médica diante desta instituição, o hospital passa funcionar como instrumento de intervenção sobre a doença e o doente.

\section{c) O tratamento}

Para os grupos de conversação a loucura é definida como transtorno, descontrole emocional, desvio de conduta, distúrbio que precisa de tratamento, e apesar dos grupos compartilharem sobre algumas mudanças no tratamento dispensado ao louco, o que ainda prevalece são os modelos biomédico, hospitalocêntrico e medicamentoso. Esta visão foi descrita por Foucault (2004) e remonta de um período em que o hospital nasce como instrumento de disciplinarização, ou seja, aqueles que desviam das normas sociais precisariam estar sob um regime disciplinar que os tornariam normais. No momento em que o hospital surge ele almeja a segregação dos indesejados e lhes oferece alguma assistência, nesse passo, a partir do século XVIII, o hospital passa a ser espaço de propriedade médica e, concomitantemente, a loucura passa a ser vista como doença.

Apesar dos participantes dos grupos terem compartilhado a respeito dos novos dispositivos substitutivos ao hospital e da importância de outros profissionais no tratamento, o que prevalece é a figura do hospital e das medicações, principalmente nos momentos de surto, em que os pacientes necessitam de controle externo.

A loucura é então vista como uma doença, apesar da Reforma Psiquiátrica e do surgimento de outras abordagens de tratamento, o que hoje ainda prevalece e que ficou marcado na experiência dos grupos é uma concepção que sugere uma fusão de saberes ao longo dos séculos. Desde o surgimento do modelo asilar no início do século XIX, com o psiquiatra Phillipe Pinel que assinalava uma mudança na percepção da loucura, antes tida como desrazão, erro e ilusão, esta passa a ser reduzida à categoria médica de doença mental com a psiquiatria se apropriando da mesma e trazendo um aparato que vai desde a construção de instituições como o manicômio, até a produção de profissionais como médicos, psicólogos e 


\section{PRIMEIROS PASSOS}

enfermeiros para lidar com ela. Instrumentos que em seus discursos consolidaram e subjugaram o louco ao poder psiquiátrico a partir dos séculos seguintes até os dias atuais (Dimenstein, 2014).

\section{d) A Reforma Psiquiátrica}

Para os grupos, a Reforma Psiquiátrica é tida como um processo de substituição dos manicômios por outras instituições que ofereçam um tratamento mais humanizado ao louco, portanto, demonstrando um conhecimento ainda restrito, visto que a proposta da Reforma Psiquiátrica é a de reformulação do modelo e paradigmas tradicionais da psiquiatria, apresentando, como fundamentos, críticas não somente às instituições clássicas, mas também ao saber médico hegemônico (Amarante, 1995).

Os grupos concordaram que a Reforma Psiquiátrica precisa avançar e trocaram o que sabem sobre as mudanças que ocorreram no decorrer dos anos, focando na questão estrutural das instituições manicomiais e na inclusão de outras profissões que atuam na assistência ao louco.

Pelbart (1990) abordou sobre o fim dos manicômios mentais como uma meta a ser alcançada, assim como o são os manicômios estruturais. Nesta linha de pensamento, ao louco deveria ser dado o direito à desrazão, que seria o direito a assumir o seu modo diferente de estar no mundo, liberando assim, sua própria subjetividade do que é dito como certo ou errado e lhe devolvendo cidadania e autonomia para vivenciar sua loucura. Seguindo esta linha de pensamento e o que propõe a Reforma Psiquiátrica, não seria necessário que o louco fosse adaptado à sociedade, mas sim, que a sociedade pudesse aceitá-lo em sua diferença.

Ainda que os grupos afirmassem que tentam atender ao louco de forma a não deixar que o medo influencie de forma negativa nos procedimentos a serem executados, foi recorrente compartilharem experiências de momentos em que estiveram frente a este louco e não sabiam como agir, que saíram correndo para longe deste ou que solicitaram o acompanhamento de outros profissionais no atendimento ao louco.

\section{Considerações finais}

Foi possível identificar que apesar das conquistas alcançadas a partir da Reforma Psiquiátrica, muitos dos modelos vigentes em séculos passados perduram nas concepções da loucura que os profissionais apresentam ainda hoje. Com isso, nota-se que as estruturas dos manicômios permanecem instaladas, seja em sua concretude, e ainda na mentalidade das pessoas, as quais continuam a acreditar que o louco precisa ser controlado, normalizado, equilibrado, para atender as demandas sociais. O louco, então, deve realizar seu tratamento de forma que consiga uma 
adequação na sociedade e não mais gere medo, estranhamento e insegurança com seu modo diferente de estar no mundo.

$\mathrm{O}$ instigante em realizar este trabalho e se propor a escutar as práticas dos profissionais foi constatar que para estes é correto extinguir os manicômios concretos desde que os loucos que nele habitavam possam ser normatizados por meio de outros instrumentos, ou seja, permanecem os manicômios mentais tão estudados por Pelbart (1990) que retiram o direito à desrazão, a liberdade de poder enlouquecer. Para romper com essas estruturas e ideologias, é preciso se dispor a conhecer a história, pois foi a partir dela que foram se construindo saberes e formas de lidar ao longo das épocas, observar o quanto já foi mudado e o que precisa ainda avançar, tendo em vista que tudo é processo e que precisamos nos inquietar e nos implicar se quisermos uma sociedade que de fato aceite o diferente. Permanecer enfrentando os manicômios, sejam eles estruturais e/ou mentais, para que possam avançar os processos de desinstitucionalização, os quais acabam não sendo garantidos pela legislação vigente.

Diante disto, como encaminhamentos, sugere-se que possamos romper com nossas próprias clausuras subjetivas, das quais falou Dimenstein (2009) e que, muitas vezes, acabam por nos levar a reproduzir os modelos de segregação através do poder que detemos ao lidarmos com o louco. Este movimento implica em um constante movimento de reflexão de nossas práticas, as quais não se dissociam daquilo que falamos sobre o louco, da forma que os apresentamos em sua loucura a esta sociedade ainda tão minada de preconceitos.

Para que isto seja possível é preciso que sejam ampliados os espaços de discussão e conversação acerca da loucura de forma que tais práticas possam ultrapassar as barreiras das áreas da Psiquiatria e da Saúde Mental e seja de fato incluída nas conversações nos demais espaços da sociedade; afinal, para que o louco seja inserido efetivamente, é preciso falar, conversar mais, fortalecer as discussões a seu respeito, apresentando-o à sociedade com seu modo diferente de se inserir nesta.

Agradecimentos: Agradeço a meus pais, meu irmão, as amigas que conheci e que me acompanharam neste período de Residência, à minha orientadora e aos profissionais das instituições envolvidas neste programa de Residência, pelo apoio, incentivos e conhecimentos compartilhados.

\section{Referências}

Amarante, P. (1995). Loucos pela vida: a trajetória da Reforma Psiquiátrica no Brasil. Rio de Janeiro: FioCruz. 


\section{PRIMEIROS PASSOS}

Dimenstein, M.M.L. (2009). Desinstitucionalizar é ultrapassar fronteiras sanitárias: o desafio da intersetorialidade e do trabalho em rede. Caderno Brasileiro de Saúde Mental. Recuperado em 18 nov.2014, de: <http://incubadora.periodicos.ufsc.br/index.php/ cbsm/article/viewFile/1016/114>.

Dimenstein, M. (2014). Psicologia no Campo da Saúde Mental. In I. F. de Oliveira, \& O.H. Yamamoto (Orgs.), Psicologia e politicas sociais: temas em debate. Belém: Ed. UFPA.

Foucault, M. (1972). História da loucura na Idade Clássica. São Paulo: Perspectiva.

Foucault, M. (2004). Microfísica do poder (20ª ed.). Rio de Janeiro: Graal.

Foucault, M. (2008). A arqueologia do saber ( $7^{\text {a }}$ ed.). Rio de Janeiro: Forense Universitária.

McNamee, S., \& Gergen, K. (1998). A terapia como construção social. Porto Alegre: Artes Médicas.

Pelbart, P. (1990). Manicômio mental: a outra face da clausura. In A. Lancetti, Saúde Loucura, 2. São Paulo: Hucitec.

Spink, P. O. (2008). Pesquisador conversador no cotidiano. Psicologia e Sociedade, 20, 70-77. Recuperado em 20 fev.2014, de <http://www.scielo.br/scielo.php?script=sci_arttext\&pid=S010271822008000400010>.

\section{Resumos}

(A General Hospital and its conceptions of madness)

The aim of this article was to survey the conceptions of madness produced by professionals working in a general hospital. Procedures: conversation groups were conducted and the results were analyzed based on Discourse Analysis and Michel Foucault's History of Madness. Conclusions: the structures of the asylums remain installed in their concreteness and in the mentality of people, who continue to believe that people suffering from madness must be controlled to meet social demands.

Keywords: Mental Health, Discourse Analysis, Conceptions of madness, General Hospital and Madness

(Un hôpital général et ses conceptions de la folie)

Le but de cet article est d'examiner les concepts de la folie de professionnels de la santé qui travaillent dans un hôpital général. Procédures: des groupes de conversation ont été menés et les résultats analysés par moyen de l'analyse du discours et l'Histoire de la Folie de Michel Foucault. Conclusions: les structures des asiles restent installées dans leur concrétude et dans la mentalité des gens qui continuent à croire que les fous doivent être contrôlés pour répondre aux exigences sociales.

Mots clés: Santé mentale, Analyse du discours, Conceptions de la folie, Hôpital Général et folie 
(Un Hospital General y sus concepciones de la locura)

Conocer las concepciones sobre la locura producidas por los profesionales que trabajan en un hospital general. Procedimientos: se llevaron a cabo grupos de conversación, y los resultados fueron estudiados desde el del Análisis del Discurso y de la Historia de la Locura de Michel Foucault. Conclusiones: las estructuras de los manicomios permanecen instaladas físicamente y en el pensamiento de las personas que siguen creyendo que el loco debe ser controlado para satisfacer las demandas sociales.

Palabras clave: Salud mental, análisis del discurso, concepciones de la locura, hospital General y la locura

(Das allgemeine Krankenhaus und seine Konzepte des Wahnsinns)

Ziel dieses Artikels ist es, die Konzepte des Wahnsinns des Gesundheitspersonals, das in einem allgemeinen Krankenhaus beschäftigt ist, zu ermitteln. Verfahren: Gesprächsgruppen wurden organisiert, Daten erfasst und die Ergebnisse analysiert, und zwar aufgrund der Diskursanalyse und Michel Foucaults Werk „Wahnsinn und Gesellschaft". Schlussfolgerungen: die Strukturen der Anstalten bleiben in ihrer konkreten Form und in der Mentalität der Menschen erhalten, welche glauben, dass der Verrückte kontrolliert werden muss, um den sozialen Anforderungen gerecht zu werden.

Schlüsselwörter: Psychische Gesundheit, Diskursanalyse, Konzepte des Wahnsinns, allgemeines Krankenhaus und Wahnsinn

\section{（综合性医院和他们有关于疯狂的观念）}

本文目的：了解在综合医院工作的专业人士有关对疯狂的概念。方法过程： 分组进行谈话, 用米歇尔. 福科的话语分析理论和他撰写的疯狂病历史 (Historia da Loucura）的著作中阐述的观点，来研究记录下来的综合医院的职业人士的分组对 话。结论: 精神病院的结构不但实际存在, 而且存在于人们的大脑里。人们, 包括 综合医院的专业人士仍然认为疯狂病人必须加以控制, 以满足社会需求。

关键词: 心理健康;话语分析;疯狂病的概念;综合医院和疯狂

Citação/Citation: Carvalho, J.D. de, \& Lins, C.B.A. (2015, junho). Um Hospital Geral e suas concepções de loucura. Revista Latinoamericana de Psicopatologia Fundamental, 18(2), 383-393.

Editor do artigo/Editor: Profa. Dra. Ana Cecília Magtaz 


\section{PRIMEIROS PASSOS}

Recebido/Received: 4.3.2015/ 3.4.2015 Aceito/Accepted: 25.3.2015 / 3.25.2015

Copyright: (C) 2009 Associação Universitária de Pesquisa em Psicopatologia Fundamental/ University Association for Research in Fundamental Psychopathology. Este é um artigo de livre acesso, que permite uso irrestrito, distribuição e reprodução em qualquer meio, desde que o autor e a fonte sejam citados / This is an open-access article, which permits unrestricted use, distribution, and reproduction in any medium, provided the original authors and sources are credited.

Financiamento/Funding: Esta pesquisa foi financiada com bolsa do Ministério da Saúde / This research was funded by the Ministério da Saúde.

Conflito de interesses/Conflict of interest: As autoras declaram que não há conflito de interesses / The authors have no conflict of interest to declare.

\section{Jhéssyca Dias de Carvalho}

Psicóloga especialista em Atenção à Saúde Mental pelo Programa de Residência Multiprofissional em Saúde - Universidade do Estado do Pará e Fundação Hospital de Clínicas Gaspar Vianna (Belém, PA, Br).

Av. Almirante Tamandaré, 1042/104 - B1. C - Campina

66023-000 Belém, PA, Br

e-mail: jhessycadias@hotmail.com

\section{Cristina Bastos Alves Lins}

Psicóloga; Mestra em Psicologia Clínica e Social pela Universidade Federal do Pará UFPA (Belém, PA, Br); Tutora do Programa de Residência Multiprofissional em Saúde Universidade do Estado do Pará e Fundação Hospital de Clínicas Gaspar Vianna (Belém, PA, $\mathrm{Br})$.

Travessa Perebebui, Conjunto Santos Dumont II, 51 - Marco

66087-830 Belém, PA, Br

e-mail: crisalvesins@yahoo.com.br 